\title{
Adult hypertrophic pyloric stenosis: case report and review
}

\author{
J F Graadt van Roggen, J H J M van Krieken
}

\begin{abstract}
A case of adult hypertrophic pyloric stenosis presented in an older female with no apparent predisposing factors which might be likely to precipitate the condition. There was a history of chronic dyspepsia and occasional episodes of vomiting. No contributory medical history was identified. Barium swallow and follow through showed a markedly reduced emptying time of the stomach. A partial gastrectomy was eventually done and on histopathological examination a diagnosis of adult hypertrophic pyloric stenosis was made.

(F Clin Pathol 1998;51:479-480)
\end{abstract}

Keywords: adult hypertrophic pyloric stenosis; pyloric stenosis

Congenital hypertrophic pyloric stenosis is not uncommon, occurring in approximately 0.25 to $0.5 \%$ of all live births. It usually presents between 3 and 12 weeks after birth.

Idiopathic adult hypertrophic pyloric stenosis is a far rarer condition but an accurate estimate of its incidence has not been reported so far. While the aetiology remains obscure, some cases probably represent persistence of a mild form of the juvenile condition into

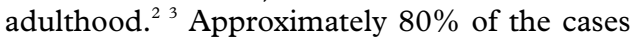
reported have occurred in males and the age of onset is extremely variable. ${ }^{2}$

We report a case occurring in an older female with no previous medical history of note relating to the digestive tract.

\section{Case report}

A 47 year old white female presented at our surgical outpatients department complaining of a two to three month history of a "full" feeling in the epigastrium, with dyspepsia and occasional episodes of mild vomiting. There was no previous medical history of note relating to the digestive tract, and specifically there was no history of peptic ulcer disease. There was no family history of cancer, and the patient kept no pets. Clinical examination was unremarkable. A barium swallow and follow through showed a markedly reduced emptying of the stomach but a specific lesion was not identified. Gastroscopy was non-contributory. A partial (distal) gastrectomy was performed, the postoperative course was uneventful, and the patient has since remained symptom-free.

\section{Gross pathology}

The surgical specimen comprised an ample distal gastric resection measuring $8 \mathrm{~cm}$ along the lesser curvature, $17 \mathrm{~cm}$ along the greater curvature, and with a maximum width between the lesser and greater curve of $8 \mathrm{~cm}$. The serosal surface was unremarkable and no localised deformities were seen. The specimen was opened along the lesser curve. The mucosal surface was unremarkable, with normal rugae proximally and no evidence of scarring, gastric ulcers, polyps, or tumours. The proximal gastric wall was supple and unremarkable on sectioning. The most distal portion of the antrum and the entire pylorus over a distance of $5 \mathrm{~cm}$ showed a marked circumferential thickening with a maximal thickness of $2 \mathrm{~cm}$ in the pylorus resulting in prominent stenosis of the pyloric lumen. A sharp and clear macroscopic demarcation between the proximal uninvolved antrum and the distal hypertrophic pylorus was not evident; rather the circumferential hypertrophic process appeared to begin gradually in the most distal part of the antrum and reach maximum thickness in the pylorus. Ample sections were taken for histology.

\section{Histopathology}

Cross sections showed a marked and diffuse circumferential thickening of the muscularis propria in the pyloric region (fig 1), with a gradual transition to the normal gastric wall proximally and duodenum distally. Although a

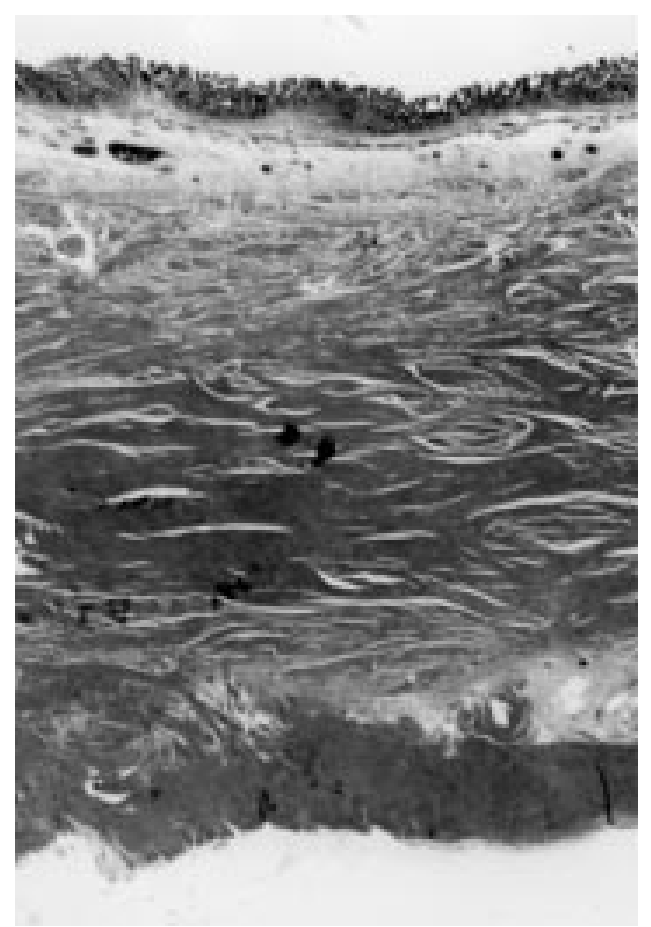

Figure 1 Low power view showing full thickness of the affected portion of the distal stomach (pylorus). Haematoxylin and eosin stain. 


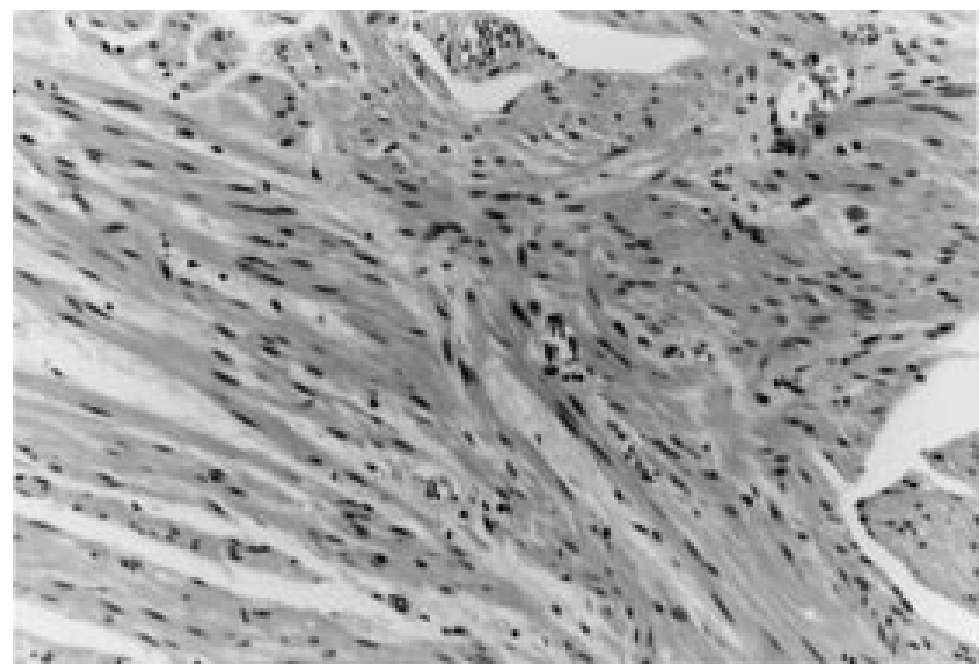

Figure 2 Cross section showing muscle hypertrophy together with a disorderly stratification (top left). Haematoxylin and eosin stain.

pre-existing normal muscular architecture could be identified within the involved segment, there was also evidence of an irregular and untidy arrangement of hypertrophic muscle fibres (fig 2). Focally, collagen deposition was present, while ganglion cells-possibly showing mild hypertrophic changes-were identified. There was no evidence of an acute or chronic gastritis, no scarring, and no evidence of carcinoma. No evidence suggestive of a stromal cell tumour was identified. Sections taken circumferentially from the hypertrophic process all showed the same features. The proliferation marker Ki-67 was negative, indicating absence of active smooth muscle replication.

\section{Discussion}

Adult pyloric obstruction has various causes that can be classified as either primary or secondary. Most reported cases, especially in the earlier part of this century, were secondary to local disease such as exuberant healing of a previous gastric or duodenal ulcer, carcinoma, extrinsic postoperative adhesions, and bezoars. $^{245}$ In these conditions there is a predominantly localised replacement by fibrous tissue, with no or very little hypertrophy of the smooth muscle in the region. ${ }^{2}$ A single case has been reported in a patient with Crohn's disease, with the assumption that this was a postinflammatory complication. ${ }^{6}$ Two cases have been reported in which the cause was found to be due to a "mucosal diaphragm." In the uncommon primary (idiopathic) form to which our case would belong, there is a total or segmental hypertrophy of the smooth muscle without any identifiable underlying disease. ${ }^{28}$ Diagnostic clues are nonspecific but an endoscopic feature (the "cervix sign") has been described which may be a pointer to the diagnosis. ${ }^{9}$ The differential diagnosis mentioned above were easily excluded on the basis of the diffuse circumferential morphology, as was the possibility of a stromal cell tumour.

There is much uncertainty and debate about the aetiology of the primary form. A certain proportion of the cases probably represents a persistence of the juvenile form, also known as congenital hypertrophic pyloric stenosis, but presenting later in life; a single case report documents the presence of the congenital form as well as the adult form in one family. ${ }^{10}$ In the remainder of cases the aetiology remains unresolved.

Treatment of choice appears to be gastric resection and Bilroth 1 reanastomosis; vagotomy and pyloroplasty has also been successfully employed.

1 Batcup G, Spitz L. A histopathological study of gastric mucosal biopsies in infantile hypertrophic stenosis. $7 \mathrm{Clin}$ Pathol 1979;32:625-8.

2 Lewin KJ, Riddell RH, Weistein WM, eds. Gastrointestinal pathology and its clinical implications, $1 \mathrm{st}$ ed. New York: Igaku-Shoin, 1992.

3 Rollins MD, Shields MD, Quinn RJ, et al. Pyloric stenosis: congenital or acquired? Arch Dis Child 1989;64:138-9.

4 Simson JN, Thomas AJ, Stoker TA. Adult hypertrophic pyloric stenosis and gastric carcinoma. Br F Surg 1986;73: 379-80.

5 Ger R. Post-operative extrinsic pyloric stenosis. BMF 1964; ii: 294 .

6 Taor RE. Adult hypertrophic pyloric stenosis and Crohn's disease. Proc $R$ Soc Med 1976;69:228

7 Chamberlain D, Addison NV. Adult pyloric obstruction due to a mucosal diaphragm. Report on two cases. BMF 1959; ii: 1381

8 Macdonald JA. Adult hypertrophic pyloric stenosis. $\mathrm{Br} \mathcal{F}$ Surg 1973;60:73-5.

9 Schuster MM, Smith VM. The pyloric "cervix sign" in adult hypertrophic pyloric stenosis. Gastrointest Endosc 1970;16: $210-11$.

10 Zavala C, Bolio A, Montalvo R, et al. hypertrophic pyloric stenosis: adult and congenital types occurring in the same family. F Med Genet 1969;6:126-8. 